\title{
Determinants of basic public health services provision by village doctors in China: using non-communicable diseases management as an example
}

\author{
Tongtong Li ${ }^{1}$, Trudy Lei ${ }^{2}$, Zheng Xie ${ }^{1^{*}}$ and Tuohong Zhang ${ }^{1}$
}

\begin{abstract}
Background: To ensure equity and accessibility of public health care in rural areas, the Chinese central government has launched a series of policies to motivate village doctors to provide basic public health services. Using chronic disease management and prevention as an example, this study aims to identify factors associated with village doctors' basic public health services provision and to formulate targeted interventions in rural China.

Methods: Data was obtained from a survey of village doctors in three provinces in China in 2014. Using a multistage sampling process, data was collected through the self-administered questionnaire. The data was then analyzed using multilevel logistic regression models.

Results: The high-level basic public health services for chronic diseases (BPHS) provision rate was $85.2 \%$ among the 1149 village doctors whom were included in the analysis. Among individual level variables, more education, more training opportunities, receiving more public health care subsidy $(\mathrm{OR}=3.856,95 \% \mathrm{Cl}: 1.937-7.678$, and $\mathrm{OR}=4.027,95 \% \mathrm{Cl}: 1.722-9.420)$, being under integrated management $(\mathrm{OR}=1.978,95 \% \mathrm{Cl}: 1.132-3.458)$, and being a New Cooperative Medical Scheme insurance program-contracted provider (OR=2.099, 95 \% Cl: 1.187-3.712) were associated with the higher BPHS provision by village doctors. Among county level factors, Foreign Direct Investment Index showed a significant negative correlation with BPHS provision, while the government funding for BPHS showed no correlation ( $P>0.100)$.

Conclusion: Increasing public health care subsidies received by individual village doctors, availability and attendance of training opportunities, and integrated management and NCMS contracting of village clinics are important factors in increasing BPHS provision in rural areas.
\end{abstract}

Keywords: Village doctors, Equity, Primary health care

\section{Background}

Village doctors are on the front lines of health care provision [1] and, at one point in time, greatly improved the equity and accessibility of public health care in rural China. A three-tiered rural health system was established in the 1960s [2], where village clinics serve the bottomtier. The "barefoot doctor" training program was implemented to create a primary workforce for public health

\footnotetext{
* Correspondence: xiezheng@bjmu.edu.cn

${ }^{1}$ School of Public Health of Peking University, 38 Xueyuan Road, Haidian

District, Beijing, P. R. China

Full list of author information is available at the end of the article
}

care [3] and provide basic medical services [4] to rural populations. These barefoot doctors were local farmers who were recruited, trained, and supported through the Cooperative Medical Scheme (CMS) [5]. CMS was a highly collective medical organization, operated privately by the barefoot doctors [6] and subsidized by public funds of local people's communes. Under such situation, barefoot doctors worked as half-peasant-half-doctor with limited medical knowledge, but they alleviated the shortage of medicine successfully. By the 1970s, they improved the quality and accessibility of health care in rural China, which was deemed by the World Health 
Organization's Declaration of Alma-Ata to be an international model for providing primary health care [7].

However, along with economic reform during the early 1980 s, the barefoot doctor system ceased and local governments took over the provision of rural public health care services. Due to the collapse of the CMS, the central government dramatically reduced health care funding in rural areas [8]. The barefoot doctors became unemployed and those who passed a qualifying examination reemerged as "village doctors" as designated by the Ministry of Health [9]. No longer were there effective incentives encouraging village doctors to provide unprofitable public health care services $[10,11]$. Instead, the economic reform forced village doctors to seek income in other ways, specifically, shifting their focus to fee-for-service medical activities [12] and profits from the $15 \%$ markup on prescribed drugs dispensed to patients [13]. Though village doctors still served as the bottom-tier of the rural health system, the government did not provide any models or guidelines to help support them through the changes to health service provision [14]. Thus, the changes brought about by privatization left local residents holding lower respect of village doctors. Since supporting basic public health services became the responsibility of local governments and due to the urban versus rural economic disparity, health equity declined greatly [15-18]. Residents in rural areas often struggled to meet their health care needs and suffered from heavy disease burden $[19,20]$. It became a serious threat to the health of rural residents in China [21-24].

Providing good quality and accessible public health care for rural population is an important issue for Chinese healthcare reform [25]. The Chinese government launched the Health Sector Reform in 2009 with one of the goals being to provide a package of basic public health services including health records creation for every resident, health education, immunization, chronic disease (hypertension and diabetes) management, severe mental diseases patient management, maternal and child health care services, elderly health care, and so forth [26]. However, there are still significant provision variations among different basic public health items. As an example, previous studies have showed that, for immunization as well as maternal and child health care services $[27,28]$ were traditionally well provided by village doctors, while the provision of chronic disease management and prevention was extremely low [29]. These newly added items of basic public health services for chronic diseases (abbreviated here as BPHS) increased the workload of village doctors naturally. In practice, however, the quantity and quality of BPHS provision vary among different village doctors $[26,30]$.

To achieve the goal of providing basic public health services, the Health Sector Reform also formulated a series of strategies to "build a strong rural health service network," such as providing more training for, strengthening management to, and improving subsidies for village doctors [31]. Providing routine training programs is the first requirement for increasing provision and improving consistency of BPHS. Content of such trainings include health care policy, standards, and BPHS quality management. As most village doctors begin to work immediately after obtaining their secondary school degree [32], on-the-job training is essential to ensure the quality of their services [33], especially regarding BPHS [30]. Fortunately, since the Health Sector Reform in 2009, the central government has required township health centers (THCs) to devise structured and tailored training programs to update village doctors' knowledge and techniques on public health services.

There are also other new political strategies incentivizing and supervising BPHS provision by village doctors. In 2003, the Chinese government initiated the $\mathrm{New} \mathrm{Co}-$ operative Medical Scheme (NCMS), a government-run voluntary insurance program for rural residents [34], which has covered almost all of the targeted population in China since 2010 [35]. However, not all village clinics are NCMS-contracted providers, thereby possibly influencing patient choice of health care provider due to availability of reimbursements, which would affect BPHS provision by village doctors [5]. Also, in 2009, integrated management was established, that is, the THCs began take on responsibility for the management of the village clinics, including medicine, personnel, finance, facilities, routine work, etc. Additionally, all work related to the public health services of village doctors was under the supervision and management of THCs, which significantly affected village doctors' income structure [5] and pushed a shift in focus of their daily work from medical services toward public health.

Lastly, subsidies given to village doctors' subsidies on BPHS is also one major strategy carried out since the Health Sector Reform. The central government created a specific fund, the "basic public health service fund", allocated to the THCs for distribution to village doctors to motivate them to provide basic public health services. The central government dictated an increase in amount of the funds from $¥ 25$ (US \$4.033) per person in the service population in 2012 to $¥ 40$ (US \$6.453) in 2015 . However, the actual subsidy received per person differs by county since local government may also add to the fund provided by the central governmental according to the local fiscal status. While the subsidy in some counties remains at national standard with no local government supplementation, in some eastern counties with sufficient supply from local financing, it reaches ¥100 (US \$16.132). Furthermore, there are also some other factors affecting village doctors' behavior collectively. For example, village doctors living in different geographic counties or counties 
with different levels of economic openness may hold different views on the provision of BPHS.

Village doctors' personal BPHS provision is deeply affected by the county-level factors, as well as by individual characteristics. However, limited studies concerning both level factors are available. Hence, this study aimed to investigate the factors associated with village doctors' BPHS provision at both individual and county levels and to provide possible policy recommendations to improve public health care equity and accessibility in rural area.

\section{Methods}

\section{Data}

This study used a multi-stage sampling design. First, three provinces were selected to represent each economic region of China (eastern, middle, and western) as previously defined by the government. Within each province, counties were designated as rich or poor based on available socioeconomic status data, then two rich counties and two relatively poor counties were chosen randomly within each designation. Health care managers helped to call all local village doctors to the THCs on the day of visit. Each THC governed approximately 20 village clinics, and each clinic generally had one village doctor (for those have two doctors, only one doctor was invited to participant), totaling 20 village doctors on average in each THC. The research team visited the selected THCs, and all village doctors present were invited to participate in the survey. To ensure confidentiality, no respondent identifiers were recorded. All respondents finished their questionnaires on their own, but research staffs were available and ready to address any questions raised by respondents. All eligible village doctors agreed to participate. The final sample consisted of 1149 village doctors in 12 county-level units with between 100 and 140 village doctors representing each county (Fig. 1). Ethics approval for this study was obtained from Peking University Health Science Center in China (protocol number IRB00001052- 14017).

\section{Measures \\ Dependent variables}

Provision of BPHS by village doctors was assessed using a questionnaire that included three items: "Do you manage hypertension diseases for local residents?", "Do you manage diabetes for local residents?", and "Do you create health records for all citizens?", all with the response categories "yes" and "no". Responses were given a value of 1 for "yes" and 0 for "no", and the sum score thus ranged from 0 to 3 . As all three are essential BPHS services [36], village doctors who scored 0,1 , or 2 were considered to be low-level BPHS providers (coded 0) and village doctors with scores of 3 were considered to be high-level providers (coded 1).

\section{Individual-level variables}

Participation in training programs was measured by: "How many times did you participate in village doctors training programs during the last 3 years?" Monthly public health care subsidy received was measured by: "How much do you earn monthly from the government for public health services?" Three categories were created from the responses: none (0), 1-300 Chinese Yuan (CNY) (1), and more than $300 \mathrm{CNY}(2)$.

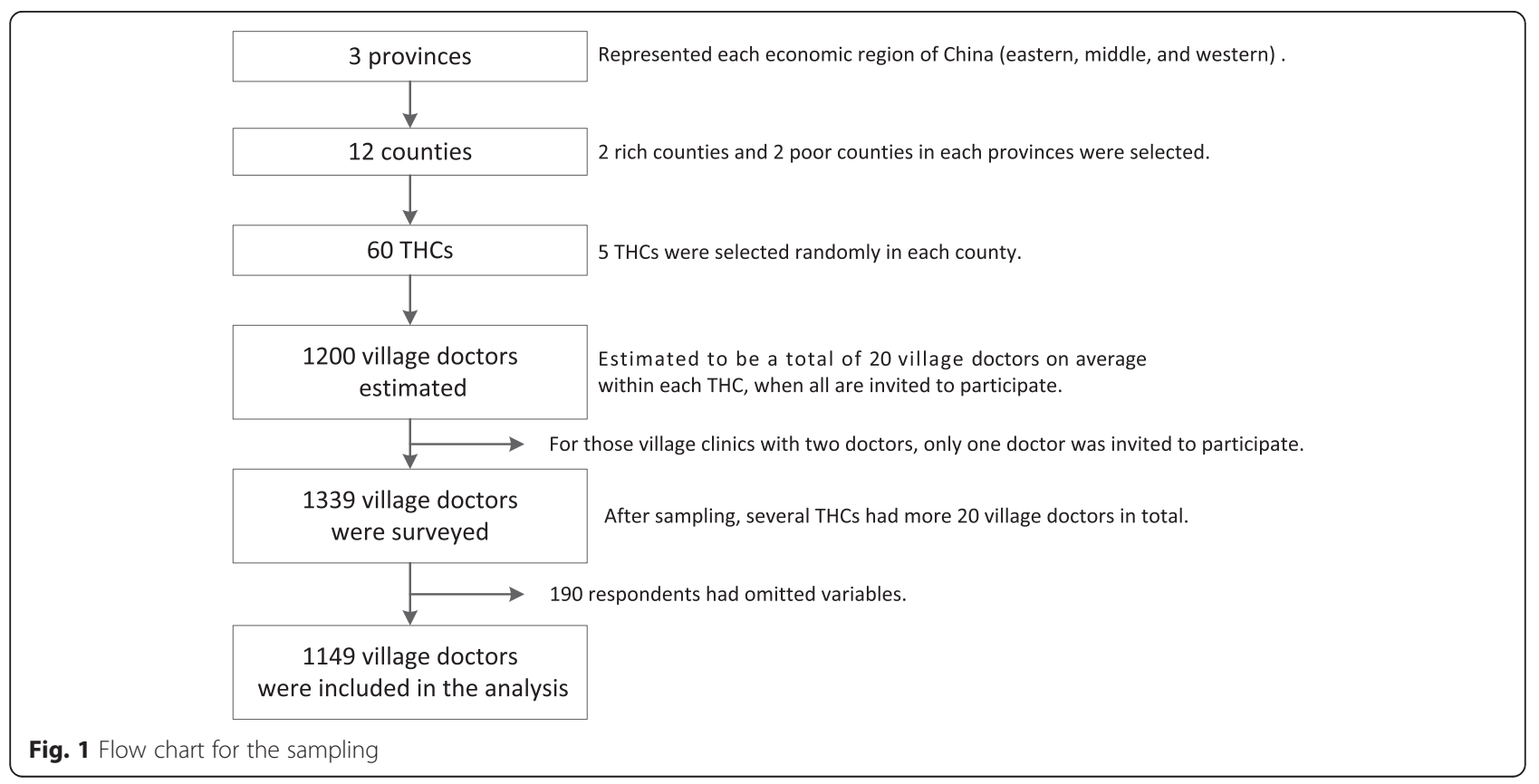


Integrated management was measured by three questions: "Do THCs manage the finances of your village clinic?", "Do THCs manage the personnel salary of your village clinic?", and "Do THCs manage medical drugs of your village clinic?" Responses for each were recorded on a three-point scale: "total", "partial", and "none". Responses were given a value of 2 for "total", 1 for "partial," and 0 for 'none', and the sum score ranged from 0 to 6 . Village clinics, which scored $0,1,2$, or 3 , were considered as low level of integrated management (coded 0 ), while village clinics with scores of 4,5 , or 6 were considered high level (coded 1).

NCMS-contracted was measured by one question: "Is your village clinic a NCMS-contracted medical institution?" with response categories 'yes' and 'no'. Responses were given a value of 1 for 'yes' and 0 for 'no'.

Control variables included age (20-39, 40-59, and 60 or over), gender, and education level (completion of junior high school or less, completion of secondary school, higher than secondary school). Participants' average monthly income ranged from 0 to $4000 \mathrm{CNY}$ and was separated into three categories of equal proportion: low, average, and high (Additional file 1).

\section{County-level variables}

Three county-level variables were included in the analysis: (i) geological characteristics, (ii) Foreign Direct Investment Index (FDI Index), the ratio between foreign direct investment and gross domestic product (GDP) in 2013, revealing the openness of the local economy [37], and (iii) funding of BPHS, from central and local government budgets, expressed as funding for each local resident (Additional file 2).

\section{Analyses}

All analyses were conducted using STATA version 12.0. Descriptive statistics were used to describe the characteristics of the study population. To determine the differences in individual variables according to BPHS provision, Chi-squared tests and t-tests were performed. To model the effects of compositional (individual level) and contextual (county level) variables on BPHS provision by village doctors, the data was fitted using a logistic regression with village doctors' reported provision of BPHS as the outcome. Odds ratios (ORs) and their $95 \%$ confidence intervals (CIs) for BPHS provision were analyzed using multilevel logistic regression models, adjusting for both individual and county level variables as fixed effects and allowing for heterogeneity between counties. A series of five models was performed with Model 1 as a null model containing no explanatory variables. Intra-class correlation coefficient (ICC) was computed to examine the necessity of fitting multilevel models. Model 2 included all the control confounders at the individual level. Model 3 and
Model 4 added individual and county level variables, respectively, into Model 2. Model 5 added both individual and county level variables into Model 2. Comparing Models 3 through 5, the impacts of compositional and contextual variables on provision of BPHS and their changes after controlling for each other were assessed.

\section{Results}

\section{Descriptive statistics of the sample}

At the individual level, a considerable number of respondents were male (75.2\%), were between 40 and 59 years old (53.1 \%), held a secondary school degree (68.1\%), and earned a monthly subsidy between 1 and $300 \mathrm{CNY}$ for public health service (59.0\%). On average, each village doctor had attended $12.7( \pm 8.791)$ trainings in the last 3 years. In regards to central policies, 671 (52.4\%) village doctors worked in a clinic with high-level integrated management and $787(68.5 \%)$ belonged to NCMS-contracted provider clinics. At the community level, more than half of the counties were in the mountain area $(62.5 \%)$ and $64.1 \%$ got $30 \mathrm{CNY}$ of BPHS funding per resident (Table 1 ).

\section{Differences in individual-level characteristics of BPHS provision}

Among 1149 participants, 979 (85.2\%) village doctors provided high-level BPHS (Table 2). The high BPHS group had more men and more members between 40 and 59 years old in comparison to those in the low BPHS group. Members of the high BPHS group had received more education and training than those in the low BPHS group. Those who earned less in total or earned less public health subsidy were more likely to belong to the low BPHS group. Village doctors who worked in NCMS-contracted village clinics and highlevel integrated management more likely belonged to the high BPHS group $(P<0.001)$.

Figure 2 presents some findings in a histogram (based on percentage of village doctors providing high-level BPHS). The percentage of high-level BPHS provision in relation to public health care monthly subsidies showed a positive trend with increased subsidy. Yet there is no significant trend regarding the percentage of high-level $\mathrm{BPHS}$ provision versus government funding for BPHS per person.

\section{Multilevel logistic regression estimates of BPHS provision}

Table 3 shows the results of multilevel logistic regression analysis models testing the individual and county level factors associated with BPHS provision. Without including any explanatory variables, $38.4 \%$ of the variance in village doctors' BPHS provision came from the county level and there was significant difference among counties (Model 1). 
Table 1 Descriptive statistics

\begin{tabular}{|c|c|c|}
\hline Variable & Sample & Percentage (\%) \\
\hline \multicolumn{3}{|l|}{ Individual level (level-1, $n=1149$ ) } \\
\hline \multicolumn{3}{|l|}{ Gender } \\
\hline Male & 864 & 75.2 \\
\hline Female & 285 & 24.8 \\
\hline \multicolumn{3}{|l|}{ Age (years) } \\
\hline 20-39 & 344 & 29.9 \\
\hline $40-59$ & 610 & 53.1 \\
\hline $60+$ & 195 & 17.0 \\
\hline \multicolumn{3}{|l|}{ Education } \\
\hline$\leq$ Junior high school & 149 & 13.0 \\
\hline Secondary school & 783 & 68.1 \\
\hline > Secondary school & 217 & 18.9 \\
\hline \multicolumn{3}{|l|}{ Average monthly income $(\mathrm{CNY})^{\mathrm{b}}$} \\
\hline Low & 392 & 34.1 \\
\hline Ordinary & 377 & 32.8 \\
\hline High & 380 & 33.1 \\
\hline Frequency of training in last 3 years & 1149 & $12.7(8.791)^{\mathrm{a}}$ \\
\hline \multicolumn{3}{|c|}{ Monthly public health care subsidy (CNY) ${ }^{\text {b }}$} \\
\hline None & 159 & 13.8 \\
\hline $1-300$ & 678 & 59.0 \\
\hline More than 300 & 312 & 27.2 \\
\hline \multicolumn{3}{|l|}{ Integrated Management } \\
\hline Low & 561 & 47.6 \\
\hline High & 671 & 52.4 \\
\hline \multicolumn{3}{|l|}{ NCMS-contracted } \\
\hline No & 362 & 31.5 \\
\hline Yes & 787 & 68.5 \\
\hline \multicolumn{3}{|l|}{ County level (level-2, $n=12$ ) } \\
\hline \multicolumn{3}{|l|}{ Geographical factor ${ }^{c}$} \\
\hline Mountain area & 8 & 62.5 \\
\hline Plain & 4 & 37.5 \\
\hline \multicolumn{3}{|l|}{ FDI Index ${ }^{d}$} \\
\hline Low & 5 & 38.6 \\
\hline Average & 3 & 28.9 \\
\hline High & 4 & 32.6 \\
\hline \multicolumn{3}{|l|}{ Funding for BPHS per person (CNY) b, c } \\
\hline Less than 30 & 2 & 14.5 \\
\hline 30 & 8 & 64.1 \\
\hline More than 30 & 2 & 21.4 \\
\hline
\end{tabular}

${ }^{a}$ Training opportunity last 3 years is a continuous variable, presented by mean (S.D.) instead of percentage

${ }^{\mathrm{b}}$ USD \$1 = CNY 6.199 (June 1, 2015)

${ }^{c}$ Aggregate variables

${ }^{d}$ Integral variables
After adding confounders, the county level variance decreased, but still remained significant (Model 2).

In Model 3, village doctors who received more education $(\mathrm{OR}=1.974,95 \% \mathrm{CI}: 1.015-3.838$, and $\mathrm{OR}=3.459$, 95 \% CI: 1.438-8.317), more training opportunities ( $\mathrm{OR}=$ 1.034, 95\%CI: 1.002-1.066), and more public health care subsidy were more likely to provide high BPHS. More specifically, village doctors who received 1-300 CNY public health care subsidy monthly provided more BPHS than those who received no subsidy $(\mathrm{OR}=3.564,95 \% \mathrm{CI}$ : $1.795-7.004)$ and those who received even more than 300 CNY per month provided even more services $(\mathrm{OR}=3.886$, 95 \% CI: 1.683-8.972). Additionally, integrated management $(\mathrm{OR}=1.911,95 \%$ CI: $1.096-3.332)$ and NCMS contracting $(\mathrm{OR}=2.005,95 \% \mathrm{CI}: 1.131-3.554)$ increased the probability of high BPHS provision of village doctors. The results were quite constant even after including county level variables (Model 5).

In Model 4, increased FDI index at the county level reduced the probability of high BPHS provision. Government funding for BPHS was not associated with village doctors' level of BPHS provision. After including individual level factors, the influence of contextual variables remained unchanged (Model 5), though the exact value of OR and CI changed slightly. Furthermore, from Models 2 to 5 , the county-level variance decreased by $62 \%$, which implied that these variables had good explanatory power for the variance in village doctors' BPHS provision.

\section{Discussion}

Our findings show that village doctors with higher education levels and more training opportunities were more likely to be high BPHS providers, consistent with prior studies in China [36, 38]. This may be because those with higher education levels and more training opportunities have better knowledge of BPHS [33, 39, 40]. Before 2009, most of the training developed by local health departments for village doctors focused on disease treatment, clinical skill, and basic health care policy [41]. However, since the Health Sector Reform, the central government has shifted the focus of training to primary health care [42], especially the norms, standards and service delivery paths of BPHS, as recommended by international studies as an effective way to improve public health services in rural areas [43, 44]. However, due to local economic limitations or personal choice, these training programs were still not necessarily available for and attended by all the village doctors in China [38]. Thus, to improve BPHS provision by village doctors, education of and training opportunities for village doctors should be increased, with a focus on knowledge about public health services. 
Table 2 The differences of individual level characteristics by BPHS provision in China

\begin{tabular}{|c|c|c|c|}
\hline Variables & Low-level BPHS ( $n=170)$ Percentage (\%) & High-level BPHS ( $n=979)$ Percentage (\%) & $P$ value $^{\mathrm{b}}$ \\
\hline Gender & & & 0.002 \\
\hline Male & 65.9 & 76.8 & \\
\hline Female & 34.1 & 23.2 & \\
\hline Age (years) & & & 0.030 \\
\hline 20-39 & 30.6 & 29.8 & \\
\hline $40-59$ & 45.9 & 54.4 & \\
\hline $60+$ & 23.5 & 15.8 & \\
\hline Education & & & $<0.001$ \\
\hline$\leq$ Junior high school & 24.1 & 11.0 & \\
\hline Secondary school & 65.3 & 68.6 & \\
\hline$>$ Secondary school & 10.6 & 20.3 & \\
\hline Average monthly income $(\mathrm{CNY})^{c}$ & & & $<0.001$ \\
\hline Low & 49.5 & 31.5 & \\
\hline Ordinary & 22.9 & 34.5 & \\
\hline High & 27.6 & 34.0 & \\
\hline Frequency of training in last 3 years ${ }^{a}$ & 11.5 & 12.9 & 0.049 \\
\hline Monthly public health care subsidy $(\mathrm{CNY})^{\mathrm{C}}$ & & & $<0.001$ \\
\hline None & 17.6 & 13.2 & \\
\hline $1-300$ & 74.2 & 56.4 & \\
\hline More than 300 & 8.2 & 30.4 & \\
\hline Integrated Management & & & $<0.001$ \\
\hline Low & 82.4 & 43.0 & \\
\hline High & 17.6 & 57.0 & \\
\hline NCMS-contracted & & & $<0.001$ \\
\hline No & 70.0 & 24.8 & \\
\hline Yes & 30.0 & 75.2 & \\
\hline
\end{tabular}

${ }^{a}$ Training opportunity last 3 years is a continuous variable, presented by mean instead of percentage

${ }^{b} P$ value by chi-square test in categorical variables and $t$-test in continuous variables

c USD \$1 = CNY 6.199 (June 1, 2015)

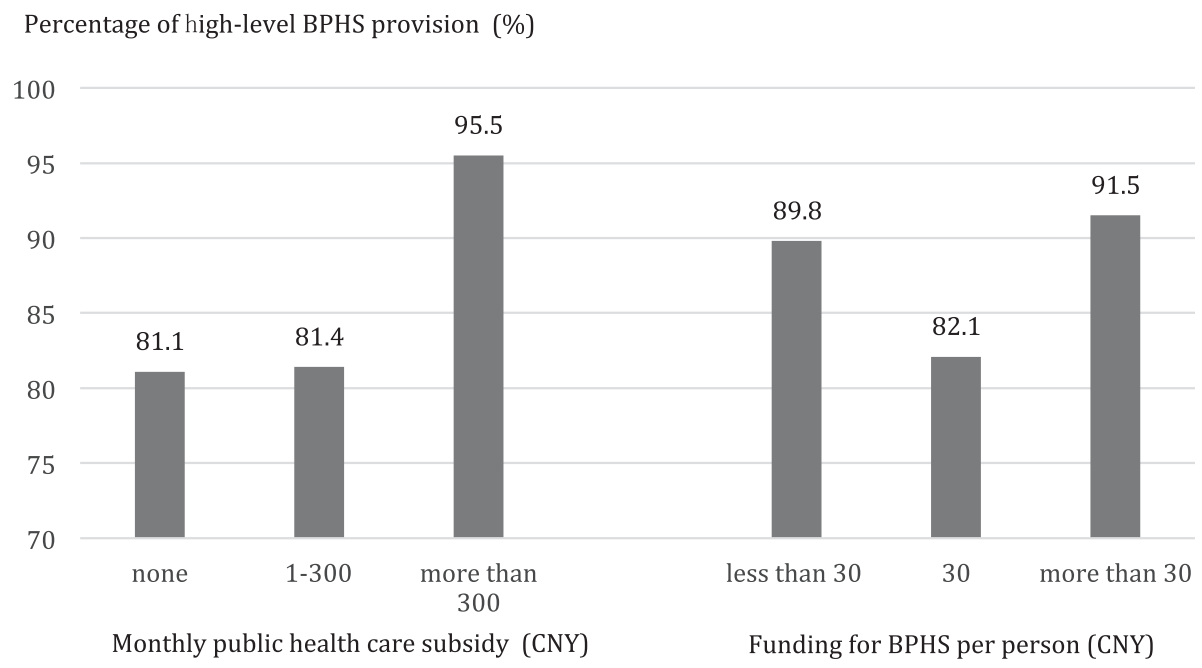

Fig. 2 Village doctors' BPHS provision level under different subsidies in China 
Table 3 Multilevel logistic regression estimates and variance components of provision of BPHS of village doctors, $\mathrm{N}=1149$ individuals nested within $N=12$ counties

\begin{tabular}{|c|c|c|c|c|c|c|c|c|c|c|}
\hline \multirow[t]{2}{*}{ Variables } & \multicolumn{2}{|l|}{ Model 1} & \multicolumn{2}{|l|}{ Model 2} & \multicolumn{2}{|l|}{ Model 3} & \multicolumn{2}{|l|}{ Model 4} & \multicolumn{2}{|l|}{ Model 5} \\
\hline & $\mathrm{OR}$ & $95 \%$ C.I. & $\mathrm{OR}$ & $95 \%$ C.I. & $\mathrm{OR}$ & $95 \%$ C.I. & $\mathrm{OR}$ & $95 \%$ C.I. & $\mathrm{OR}$ & $95 \%$ C.I. \\
\hline \multicolumn{11}{|l|}{ Individual level } \\
\hline \multicolumn{11}{|l|}{ Gender } \\
\hline \multicolumn{11}{|l|}{ Male (ref) } \\
\hline Female & & & 0.828 & $(0.525,1.304)$ & 0.842 & $(0.521,1.360)$ & 0.840 & $(0.533,1.322)$ & 0.860 & $(0.533,1.387)$ \\
\hline \multicolumn{11}{|l|}{ Age (years) } \\
\hline \multicolumn{11}{|l|}{ 20-39 (ref) } \\
\hline $40-59$ & & & 1.433 & $(0.908,2.262)$ & 1.467 & $(0.904,2.381)$ & 1.445 & $(0.916,2.281)$ & 1.474 & $(0.908,2.390)$ \\
\hline $60+$ & & & 1.495 & $(0.744,3.003)$ & 1.697 & $(0.802,3.594)$ & 1.494 & $(0.745,2.996)$ & 1.685 & $(0.799,3.555)$ \\
\hline \multicolumn{11}{|l|}{ Education } \\
\hline \multicolumn{11}{|l|}{$\leq$ Junior high school (ref) } \\
\hline Secondary school & & & $1.694^{*}$ & $(0.905,3.171)$ & $1.974^{* *}$ & $(1.015,3.838)$ & 1.681 & $(0.899,3.143)$ & $1.926^{*}$ & $(0.993,3.737)$ \\
\hline > Secondary school & & & $2.628^{* *}$ & $(1.160,5.955)$ & $3.459^{* * *}$ & $(1.438,8.317)$ & $2.656^{* *}$ & $(1.173,6.012)$ & $3.443^{* * *}$ & $(1.434,8.266)$ \\
\hline \multicolumn{11}{|l|}{ Average monthly income } \\
\hline \multicolumn{11}{|l|}{ Low (ref) } \\
\hline Ordinary & & & $1.853^{* *}$ & $(1.104,3.111)$ & 1.379 & $(0.796,2.389)$ & $1.841^{* *}$ & $(1.098,3.087)$ & 1.351 & $(0.781,2.336)$ \\
\hline High & & & 1.110 & $(0.680,1.812)$ & 0.992 & $(0.584,1.687)$ & 1.114 & $(0.684,1.817)$ & 0.978 & $(0.577,1.660)$ \\
\hline $\begin{array}{l}\text { Frequency of training in last } \\
3 \text { years }\end{array}$ & & & & & $1.034^{* *}$ & $(1.002,1.066)$ & & & $1.034^{* *}$ & $(1.003,1.066)$ \\
\hline \multicolumn{11}{|c|}{ Monthly public health care subsidy (CNY) } \\
\hline \multicolumn{11}{|l|}{ None (ref) } \\
\hline $1-300$ & & & & & $3.546^{* * *}$ & $(1.795,7.004)$ & & & $3.856^{* * *}$ & $(1.937,7.678)$ \\
\hline More than 300 & & & & & $3.886^{* * *}$ & $(1.683,8.972)$ & & & $4.027^{* * *}$ & $(1.722,9.420)$ \\
\hline \multicolumn{11}{|l|}{ Integrated Management } \\
\hline \multicolumn{11}{|l|}{ Low (ref) } \\
\hline High & & & & & $1.911^{* *}$ & $(1.096,3.332)$ & & & $1.978^{* *}$ & $(1.132,3.458)$ \\
\hline \multicolumn{11}{|l|}{ NCMS-contracted } \\
\hline \multicolumn{11}{|l|}{ No (ref) } \\
\hline Yes & & & & & $2.005^{* *}$ & $(1.131,3.554)$ & & & $2.099^{* *}$ & $(1.187,3.712)$ \\
\hline \multicolumn{11}{|l|}{ County level } \\
\hline Geographical factor & & & & & & & & & & \\
\hline Mountain area (ref) & & & & & & & & & & \\
\hline Plain & & & & & & & 1.995 & $(0.390,10.201)$ & 2.761 & $(0.602,12.671)$ \\
\hline FDI Index & & & & & & & & & & \\
\hline Low(ref) & & & & & & & & & & \\
\hline Average & & & & & & & 1.276 & $(0.172,9.470)$ & 1.498 & $(0.239,9.394)$ \\
\hline High & & & & & & & $0.159^{* *}$ & $(0.032,0.784)$ & $0.289^{*}$ & $(0.071,1.179)$ \\
\hline Funding for BPHS per person & & & & & & & & & & \\
\hline Less than 30 (ref) & & & & & & & & & & \\
\hline 30 & & & & & & & 0.726 & $(0.098,5.370)$ & 0.324 & $(0.051,2.045)$ \\
\hline More than 30 & & & & & & & 0.334 & $(0.030,3.706)$ & 0.233 & $(0.026,2.086)$ \\
\hline Variance components & & & & & & & & & & \\
\hline County level variance & $2.047^{* * *}$ & & $1.957^{* * *}$ & & $1.604^{* * *}$ & & $1.118^{* * *}$ & & $0.772^{* * *}$ & \\
\hline Intra-class correlation & 0.384 & & 0.373 & & 0.328 & & 0.254 & & 0.190 & \\
\hline
\end{tabular}


The results show that monthly BPHS subsidies at the individual level exhibit the most consistently positive correlation with the BPHS outcome. This means that financial incentives still play an essential role in scaling up BPHS provision by village doctors. Although China has grown to be the second largest economy in the world [45], with the increase in income per capita, village doctors still earn a relatively low income. Their income is not only lower than those working in THCs [46], but also lower in respect to their own income of previous years $[30,47,48]$, due to the switch to the fee-forservice payment model after the economic reform in the 1980s. Therefore, without any financial support from the government, they have little incentive to provide public health services [49]. Thus, the special subsidy for BPHS, about ¥200-400 (US \$32.263-64.527) per month, is a crucial component of their total income and a strong motivator for providing BPHS to local residents.

Compared to BPHS subsidies at the individual level, the government funding for each resident within the service population on the county level shows no resulting difference in BPHS provision by village doctors. This may be due to inconsistency in the availability and amount of government funding received by village doctors. First of all, this government funding of BPHS for local residents is based on both central and local government finance and varied in different areas depending upon local fiscal capacity [42]. For example, the government funding for BPHS in Beijing is triple the national standard [50], while in other provinces it is near or lower than national standard. This is one major obstacle to providing high-level public health services in many rural areas [51]. Secondly, although THCs are required to allocate no less than $40 \%$ of government funding of BPHS to village doctors, the specific proportion actually received is uncertain [48]. A previous study in China showed only a small portion is used to compensate village doctors [26], which would fail to motivate village doctors to provide public health services. Thus, more funding should be allocated to village doctors directly in order to improve BPHS provision in rural China long-term.

Village clinics under high-level integrated management and NCMS contracting were also more likely to provide high provision of BPHS by village doctors after controlling for other factors. This may be due to the supervision and support of integrated management as well as the outpatient reimbursement of NCMS [52]. Integrated management is a newly implemented policy in the rural health care service scheme, aiming to manage village doctors as ordinary primary health care providers under THCs. Under this policy, village doctors are not only supervised by the public health service standards of THCs [53], but also supported by advantageous knowledge and resources through contracts with THCs [54]. Since the integrated management policy's creation in 2009, it has expanded considerably and may cover all village clinics in the future. The NCMS insurance program includes considerable compensation for outpatient care of rural residents and is heavily subsidized by central, provincial, and county governments [55]. NCMS covers care at THCs and county-level hospitals, which are public, government-owned institutions in China. The village clinics, however, are not all covered by this policy. Our data showed that only $68.5 \%$ village clinics among the total surveyed were NCMS-contracted medical institutions. Consequently, patients who do not live near any NCMS-contracted village clinics would be motivated by NCMS outpatient reimbursement rates to go to THCs and county-level hospitals for minor illnesses rather than to their village clinics [56]. Thus, village doctors who work without contracts with NCMS would lose their opportunities to provide BPHS and face more challenges to ensure the public health care of local residents. Fortunately, both integrated management and the NCMS are major policies of the Health Sector Reform in China with a trend towards expanded coverage of more village clinics in the future. Together, these changes show positive steps in policy advancement toward the improvement of BPHS provision by village doctors.

Like other rapidly developing countries, China is experiencing an increase in chronic health issues along with the resulting social and economic burdens [57, 58]. However, before the Health Sector Reform in 2009, chronic disease prevention and management received relatively less attention compared with other basic public health services. Traditional public health care services such as immunization and maternal- and child-care have experienced numerous intervention projects and have been well-provided nationwide for a long period [59], while chronic disease prevention and management is only a newly added item with a low starting point towards achieving accessibility and equity of provision, especially in rural areas. Fortunately, the central government and medicine relative organizations in China have already begun to increase awareness of this issue and strengthen support gradually. However, our results showed that the coherence of current chronic disease prevention and management policies are not ideal, with space for improvement as discussed above. Thus, other political, financial, and material support is necessary to improve the remuneration and mobilization of village doctors, and realize the goal of public health service equalization eventually.

There are several limitations in this study. Firstly, although the selected provinces are generally representative of the typical economic and health development characteristics in China, the study area is limited to three provinces, which may compromise the generalizability of the findings. A larger geographical area would have more 
external validity. Secondly, the cross-sectional nature of the study dictates that only correlation, rather than causation, can be studied. In the future, it would be useful to perform a more comprehensive study to further research financial incentives of village doctors' BPHS provision and how health care policies influence them.

\section{Conclusion}

There is considerable room for improvement regarding the factors associated with village doctors' BPHS provision. Specifically, three key areas have been elucidated in order to increase BPHS provision in rural areas: (i) increasing public health care subsidies for village doctors and ensuring transparency in the allocation of government funding to village clinics, (ii) mobilizing resources and village doctors to provide and attend ample training programs, and (iii) expanding NCMS contracting with village clinics and partnering with THCs for integrated management. Expansion and enforcement of current policies by the Chinese government to address these factors is essential toward helping to improve accessibility and quality of basic public health care in rural areas, reduce urban-rural disparities, and increase health equity nationwide. In addition, as urbanization grows globally, these findings about the Chinese health care reform experience may also be relevant for other developing countries in recognizing possible rural area health provision shortfalls and designing effective strategies to ensure public health care.

\section{Additional files}

Additional file 1: Questionnaire of village doctors in China. (PDF 41
$\mathrm{~kb}$ )
Additional file 2: County level questionnaire of village doctors in
China.
(PDF $20 \mathrm{~kb}$ )

\section{Abbreviations}

BPHS: basic public health services for chronic diseases; CMS: cooperative medical scheme; CNY: Chinese Yuan; FDI Index: foreign direct investment index; GDP: gross domestic product; NCMS: new cooperative medical scheme; THCs: township health centers.

\section{Competing interests}

The authors declare that they have no competing interests.

\section{Authors' contributions}

$T T L, Z X$ and THZ participated in the research design and project implementation. $T T L$ and $Z X$ participated in the data analysis. TTL wrote the original text. TL and ZX revised the manuscript. All authors read and approved the final manuscript.

\section{Acknowledgments}

We thank Hai Fang, He Chen (Peking University), and Xiwei Wu (Renmin University of China) for their advice on paper structure. We are grateful to the study participants in Shanxi, Guangxi, and Shandong province in China. We also thank Yifan Zhen, Ke Ning, Xiangmeng Li, and Deying Zhu for their participation in data collection.
This study was supported by the National Natural Science Foundation of China (NSFC). Grant number: 71403006.

\section{Author details}

${ }^{1}$ School of Public Health of Peking University, 38 Xueyuan Road, Haidian District, Beijing, P. R. China. ${ }^{2}$ School of Public Health of Columbia University, New York, USA.

Received: 5 August 2015 Accepted: 22 January 2016

Published online: 04 February 2016

\section{References}

1. Sun C, Chai W, Zhou Y, Wang Y. Challenges Facing China's Public Health and Primary Health Care in Health Care Reform. J Vasc Med Surg. 2014;2:e114.

2. Gu XY, Tang SL, Cao SH. The financing and organization of health services in poor rural China: a case study in Donglan County. Int J Health Plann Manage. 1995;10(4):265-82.

3. Cui WY. China's Village Doctors Take Great Strides: Village Doctors Have Dramatically Improved Access to Health Care in China's Rural Communities over the Last Few Decades. B World Health Organ. 2008;86(12):914.

4. Liu Y, Hsiao WC, Li Q, Liu X, Ren M. Transformation of China's rural health care financing. Soc Sci Med. 1995;41 (8):1085-93.

5. Zhang S, Zhang W, Zhou H, Xu H, Qu Z, Guo M, et al. How China's new health reform influences village doctors' income structure: evidence from a qualitative study in six counties in China. Human Resource for Health. 2015; 13(1):26.

6. Witter S, Garshong B, Ridde V. An exploratory study of the policy process and early implementation of the free NHIS coverage for pregnant women in Ghana. Int J Equity Health. 2013;12(5):898.

7. World Health Organization. Declaration of Alma-Ata, 1978. Available at: http://www.euro.who.int/en/publications/policy-documents/declarationof-alma-ata,-1978. Accessed 29 Jan 2016.

8. Sun X, Jackson S, Carmichael G, Sleigh AC. Catastrophic medical payment and financial protection in rural China: evidence from the New Cooperative Medical Scheme in Shandong Province. Health Econ. 2009;18(1):103-19.

9. Li X, Chongsuvivatwong V, Xia X, Sangsupawanich P, Zheng W, Ma K. Revisiting current "barefoot doctors" in border areas of China: system of services, financial issue and clinical practice prior to introducing integrated management of childhood illness (IMCI). BMC Public Health. 2012:12(1):620.

10. Bloom G. Building institutions for an effective health system: lessons from China's experience with rural health reform. Soc Sci Med. 2011;72(8):1302-9.

11. Liu X, Mills A. The effect of performance-related pay of hospital doctors on hospital behaviour: a case study from Shandong, China. Hum Resour Health. 2005;3(11):1-12.

12. Bloom G, Xingyuan G. Health sector reform: lessons from China. Soc Sci Med. 1997:45(3):351-60

13. Wang $H$, Zhang L, Yip W, Hsiao W. An experiment in payment reform for doctors in rural China reduced some unnecessary care but did not lower total costs. Health Affair. 2011;30(12):2427-36.

14. Geyndt W, Zhao X, Liu S. 1992. From barefoot doctor to village doctor in rural China. Available at: http://www-wds.worldbank.org/external/default/ WDSContentServer/WDSP/IB/1999/10/14/000178830 98101904142487/ Rendered/PDF/multi_page.pdf. Accessed 29 Jan 2016.

15. Han $Y$, Wei J, Song $X$, Sarah BJ, Wen C, Zheng X. Accessibility of primary health care workforce in Rural China. Asia Pac J Public Health. 2012;24(5):833-47.

16. Jin J, Wang J, Ma X, Wang Y, Li R. Equality of Medical Health Resource Allocation in China Based on the Gini Coefficient Method.[J]. Iran J Public Health. 2015;44(4):445-57.

17. Anand S, Fan VY, Zhang J, Zhang L, Ke Y, Dong Z, et al. China's human resources for health: quantity, quality, and distribution. Lancet. 2008; 372(9651):1774-81.

18. Blumenthal D, Hsiao W. Privatization and its discontents-the evolving Chinese health care system. New Engl J Med. 2005;353(11):1165-70.

19. Tang S, Meng Q, Chen L, Bekedam H, Evans T, Whitehead M. Tackling the challenges to health equity in China. Lancet. 2008;372(9648):1493-501.

20. Peng R, Ling L, He Q. Self-rated health status transition and long-term care need, of the oldest Chinese. Health Policy. 2010;97(2):259-66.

21. Pan $X$, Dib HH, Wang $X$, Zhang H. Service utilization in community health centers in China: a comparison analysis with local hospitals. BMC Health Serv Res. 2006;6(1):93. 
22. Wang H, Gusmano MK, Cao Q. An evaluation of the policy on community health organizations in China: will the priority of new healthcare reform in China be a success? Health Policy. 2011;99(1):37-43.

23. Ling RE, Liu F, Lu XQ, Wang W. Emerging issues in public health: a perspective on China's healthcare system. Public Health. 2011;125(1):9-14.

24. Hu S, Tang S, Liu Y, Zhao Y, Escobar M, de Ferranti D. Reform of how health care is paid for in China: challenges and opportunities. Lancet. 2008; 372(9652):1846-53.

25. China's major health challenge: control of chronic diseases. Lancet. 2011; 378(9805): 1778.

26. Ding $Y$, Smith HJ, Fei $Y, X u$ B, Nie S, Yan W, et al. Factors influencing the provision of public health services by village doctors in Hubei and Jiangxi provinces China. Bull World Health Org Suppl. 2013;91(1):64-9.

27. Li X, Cochran C, Lu J, Shen J, Hao C, Wang Y, et al. Understanding the shortage of village doctors in China and solutions under the policy of basic public health service equalization: evidence from Changzhou. Int J Health Plann Manage. 2014.

28. Li J, Kang LN, Li B, Pang Y, Huang R, Qiao YL. Effect of a group educational intervention on rural Chinese women's knowledge and attitudes about human papillomavirus (HPV) and HPV vaccines. BMC Cancer. 2015;15.

29. Xiao N, Qian L, Tang X, Tang S. A community-based approach to noncommunicable chronic disease management within a context of advancing universal health coverage in China: progress and challenges. BMC Public Health. 2014;14(Suppl2):1-6.

30. Zhang $Y$, Chen M, Shi X. Challenges of basic public health services provided by village doctors in Guizhou, China. Asia Pac J Public Health. 2015: 1865670652.

31. Fang P, Liu X, Huang L, Zhang X, Zi F. Factors that influence the turnover intention of Chinese village doctors based on the investigation results of Xiangyang City in Hubei Province. Int J Equity Health. 2014;13(1):1-9.

32. He G, He G. The prevalence and incidence of latent tuberculosis infection and its associated factors among village doctors in China. Journal of Microbiology Immunology \& Infection. 2015;48:S26

33. Xu H, Zhang W, Zhang X, Qu Z, Wang X, Sa Z, et al. Longitudinal study of rural health workforce in five counties in China: research design and baseline description. Hum Resour Health. 2013;11(1):17.

34. Yip W, Hsiao WC. Non-evidence-based policy: how effective is China's new cooperative medical scheme in reducing medical impoverishment? Soc Sci Med. 2009;68(2):201-9.

35. Yip W, Hsiao WC. The Chinese health system at a crossroads. Health Affair. 2008;27(2):460-8.

36. Li X, Cochran C, Lu J, Shen J, Hao C, Wang Y, et al. Understanding the shortage of village doctors in China and solutions under the policy of basic public health service equalization: evidence from Changzhou. Int J Health Plann Manage. 2015;30(1):E42-55.

37. Chen $C$, Chang $L$, Zhang $Y$. The role of foreign direct investment in China's post-1978 economic development. World Dev. 1995;23(4):691-703.

38. Zhang Z, Zhan X, Li Y, Hu R, Yan W. Web-Based Training for Primary Healthcare Workers in Rural China: A Qualitative Exploration of Stakeholders' Perceptions. 2015.

39. Yang J, Guo A, Wang Y, Zhao Y, Yang X, Li H, et al. Human resource staffing and service functions of community health services organizations in China. The Annals of Family Medicine. 2008;6(5):421-7.

40. Hongoro C, McPake B. How to bridge the gap in human resources for health. Lancet. 2004;364(9443):1451-6.

41. Dong L, Wang D, Gao J, Yan H. Doctor's injection prescribing and its correlates in village health clinics across 10 Provinces of Western China. J Public Health UK. 2011;r19.

42. Yip WC, Hsiao WC, Chen W, Hu S, Ma J, Maynard A. Early appraisal of China's huge and complex health-care reforms. Lancet. 2012;379(9818):833-42.

43. Crosato KE, Leipert B. Rural women caregivers in Canada. Rural Remote Health. 2006;6(2):52.

44. Malhotra C, Malhotra R, Østbye T, Subramanian SV. Maternal Autonomy and Child Health Care Utilization in India Results From the National Family Health Survey. Asia Pac J Public Health. 2014;26(4):401-13.

45. Zhu J, Zhou Q, Wang Y, Dai Y, Zhu J, Yu C, et al. Prevalence of fatty liver disease and the economy in China: A systematic review. World J Gastroenterol. 2015;21(18):5695.

46. Hung L, Shi L, Wang H, Nie X, Meng Q. Chinese primary care providers and motivating factors on performance. Fam Pract. 2013;30(5):576-86.
47. Meng Q, Yuan J, Jing L, Zhang J. Mobility of primary health care workers in China. Hum Resour Health. 2009;7(1):24.

48. Zhou H, Zhang W, Zhang S, Wang F, Zhong Y, Gu L, et al. Health providers' perspectives on delivering public health services under the contract service policy in rural China: evidence from Xinjian County. BMC Health Serv Res. 2015;15(1):75.

49. Bloom G, Kanjilal B, Peters DH. Regulating health care markets in China and India. Health Affair. 2008;27(4):952-63.

50. Yin D, Wong ST, Chen W, Xin Q, Wang L, Cui M, et al. A model to estimate the cost of the National Essential Public Health Services Package in Beijing China. BMC Health Serv Res. 2015;15(1):1-7.

51. Wang Y, Shen JJ, Mei S, Moseley CB, Lu J, Lin F, et al. Why healthcare became so expensive in China? The transformation of healthcare financing during Chinese economic development. International Journal of Public Policy. 2012;8(1-3):4-20

52. Wagstaff A, Lindelow M, Jun G, Ling X, Juncheng Q. Extending health insurance to the rural population: An impact evaluation of China's new cooperative medical scheme. J Health Econ. 2009;28(1):1-19.

53. Wang Q, Wang W, Yan F. Compensation and welfare of village doctors under integrated management of township and village health facilities. Chinese Rural Health Service Administration. 2011.

54. Zhu YP, Miao YU, Yang FQ, Zhou JD, Yang J, Zhao Q. The feasibility of developing a syndromic surveillance system in rural China: A case study of two counties in Jiangxi province. Chinese Journal of Health Policy. 2013;6(4):60-5.

55. Yuan S, Rehnberg C, Sun X, Liu X, Meng Q. Income related inequalities in New Cooperative Medical Scheme: a five-year empirical study of Junan County in China. Int J Equity Health. 2014;13(38):10-1186.

56. Zhang L, Wang Z, Qian D, Ni J. Effects of changes in health insurance reimbursement level on outpatient service utilization of rural diabetics: evidence from Jiangsu Province China. BMC Health Serv Res. 2014;14(1):185.

57. Wang X, Guo J, Zhang X, Qu Z, Tian D, Ma S. The effects of depression and chronic diseases on the work outcomes of employees: a prospective study in Northwest China. Public Health. 2014;128(8):734-42.

58. Cai L, He J, Song Y, Zhao K, Cui W. Association of obesity with socio-economic factors and obesity-related chronic diseases in rural southwest China. Public Health. 2013;127(3):247-51.

59. Ding Y, Li XT, Xie F, Yang YL. Survey on the Implementation of Preconception Care in Shanghai, China. Paediatric \& Perinatal Epidemiology. 2015.

\section{Submit your next manuscript to BioMed Central and we will help you at every step:}

- We accept pre-submission inquiries

- Our selector tool helps you to find the most relevant journal

- We provide round the clock customer support

- Convenient online submission

- Thorough peer review

- Inclusion in PubMed and all major indexing services

- Maximum visibility for your research

Submit your manuscript at www.biomedcentral.com/submit
Biomed Central 